This PDF is a selection from an out-of-print volume from the National Bureau of Economic Research

Volume Title: Inflation, Tax Rules, and Capital Formation

Volume Author/Editor: Martin Feldstein

Volume Publisher: University of Chicago Press

Volume ISBN: 0-226-24085-1

Volume URL: http://www.nber.org/books/feld83-1

Publication Date: 1983

Chapter Title: Inflation, Tax Rules, and the Prices of Land and Gold

Chapter Author: Martin Feldstein

Chapter URL: http://www.nber.org/chapters/c11337

Chapter pages in book: (p. 221 -228) 


\section{Inflation, Tax Rules, and the Prices of Land and Gold}

\subsection{Introduction}

Traditional theory implies that the relative price of consumer goods and of such real assets as land and gold should not be permanently affected by the rate of inflation. A change in the general rate of inflation should, in equilibrium, cause an equal change in the rate of inflation for each asset price. The experience of the past decade has been very different from the predictions of this theory: the prices of land, gold, and other such stores of value have increased by substantially more than the general price level. ${ }^{1}$ The present paper presents a simple theoretical model that offers an explanation of the positive relation between the rate of inflation and the relative price of such real assets.

More specifically, the analysis here shows that, in an economy with an income tax, an increase in the expected rate of inflation causes an immediate increase in the relative price of such "store of value" real assets. What we have observed in the past decade can thus be understood as both (1) a series of transitions to higher relative asset prices whenever there was an increase in expected inflation, and (2) the traditional rise in these

Reprinted by permission from Journal of Public Economics 14 (December 1980): 309-18.

This paper is part of the NBER study of capital formation and the project on the changing role of debt and equity finance. I am grateful to the NBER and the National Science Foundation for financial support.

1. From 1968 to 1977 , the consumer price level rose 74 percent. During the same period, the price of gold rose from $\$ 39$ an ounce to more than $\$ 147$ an ounce, an increase of 250 percent. According to the investment bankers Salomon Bros. (1978), the price of farmland rose 150 percent while the price of housing rose 110 percent. 
asset prices in proportion to the general price level while the expected inflation rate remained constant. ${ }^{2}$

The behavior of real asset prices discussed in this paper is thus a further example of the non-Fisherian response to inflation of capital markets in an economy with income taxes. ${ }^{3}$ In earlier papers I showed how the traditional theory of interest rates and share prices must also be changed because of the important role that income taxes now play in our economy. ${ }^{4}$ More generally, these studies show the substantial nonneutrality of inflation in our economy.

The paper begins in section 12.2 with a simple model of the price of land and its relation to inflation. This model assumes that land and bonds are perfect substitutes in investors' portfolios. The real net yields on both types of assets must therefore be equal. Section 12.3 presents a more general portfolio equilibrium model in which assets are not assumed to be perfect substitutes. The effect of inflation on the prices of both gold and land is investigated. In order to focus on the role of taxes, the analysis ignores other important determinants of asset prices including commodity speculation, the fear of hyperinflation, and the possibility of increased supply.

\subsection{The Price of Land: A First Approximation}

Consider first a simple stationary economy with no inflation. There is a single produced good that can be either consumed or used in production. The population and the capital stock remain constant and there is no technical progress. ${ }^{5}$ The lack of inflation implies that the nominal stock of money remains unchanged. The quantity of land is, of course, also fixed.

If land and real capital are perfect substitutes in investors' portfolios, the relative price of a unit of land $\left(p_{L}\right)$ and of the produced good $(p)$ must equate their relative yields. ${ }^{6}$ If the marginal product of a unit of land in

2. The observed increase in the relative price of these assets may also reflect the increased uncertainty of future inflation rates as well as purely speculative movements that cause relative prices to depart from their long-run equilibrium. The current model ignores these issues.

3. Fisher s analyses of the effects of inflation (1930) were of course written when income taxes were much less important than they are today.

4. On interest rates, see Feldstein (1976; chap. 3 above) and Feldstein, Green, and Sheshinski (1978; chap. 4 above); see also Darby (1975). On the negative relation between expected inflation and the level of share prices. see Feldstein (1980b, $d$; chaps. 10 and 11 above).

5. I assume a stationary economy to avoid the extra complexity of valuing land as it becomes continually scarcer relative to the labor force and the capital stock. In a growing economy, the value of land depends on the form of technical progress. Note that the assumption of a fixed capital stock precludes the effect of land value on real capital accumulation discussed in Feldstein (1977).

6. Since we are currently examining an equilibrium at a point in time, the notation could be simplified by using the produced good as numeraire. It is, however, natural to use money as the numeraire since the analysis will soon deal with a changing price level. 
terms of the produced good is $p F_{L}$, the pretax return on land is $p F_{L} / p_{L}$. If this return is subject to personal tax at rate $\theta$, the net return on land is $(1-\theta) p F_{L} / p_{L}$ ? Similarly, the net return on real capital is $(1-\theta) p F_{k} / p$, where $p F_{k}$ is the marginal product of capital in terms of the produced good. ${ }^{8}$ The equality of the net returns on land and real capital

$$
\frac{(1-\theta) F_{L}}{p_{L}}=\frac{(1-\theta) F_{k}}{p}
$$

obviously implies that the price of land relative to the price of the produced good is just equal to the ratio of their marginal products:

$$
\frac{p_{L}}{p}=\frac{F_{L}}{F_{k}}
$$

Consider what happens if the government suddenly adopts a policy of increasing the money supply at rate $\pi$. For simplicity, assume that the new rate of inflation is expected to continue indefinitely. In the new equilibrium, the prices of both the produced good and land will increase at this rate:

$$
\frac{\dot{p}}{p}=\frac{\dot{p}_{L}}{p_{L}}=\pi
$$

But before this equation is established, the relative prices of land and of the produced good must change in order to preserve the equality of the net-of-tax real yields. Since inflation does not alter the pretax real yields, the relative prices of the two assets in the new equilibrium depends on the extent to which inflation changes real tax rates.

There are typically three important ways in which inflation changes effective tax rates. First, increases in the nominal value of assets are taxed as capital gains when the assets are sold; the letter $c$ will be used to denote the equivalent accrual rate of tax on such nominal gains. Note that the assumption of a stationary economy implies that there are no real capital gains. The net of tax nominal rate of capital gain is thus $(1-c) \pi$ for both assets. Second, depreciation of capital for tax purposes is based on the original cost of the asset rather than the cost of replacement. With even moderate rates of inflation, this causes a substantial reduction in the net of tax return; this will be approximated linearly by writing the real return net of income tax (but not net of capital gains tax) as $(1-\theta)\left(F_{k}-\lambda \pi\right) .{ }^{9}$ Third, firms are permitted to deduct nominal interest payments in calcu-

7. If there is a separate property tax based on the value of land, this would be reduced by a constant. Allowing for such a tax would not alter any of the conclusions of this paper.

8. Note that the price of the capital good is the same as the price of consumer goods.

9. This linear form is an approximation since $\lambda$ itself depends on both the rate of inflation and the rate of depreciation. For a discussion of this approximation in the more general context of an economy with a corporate income tax as well as a personal income tax, see the appendix by Alan Auerbach in Feldstein, Green, and Sheshinski (1978; chap. 4 above). 
lating taxable profits while individuals are taxed on nominal interest income; since bonds have not yet been introduced in the model, I will begin by ignoring this third aspect but will return to it later in this section.

The net nominal rate of return on land is thus $(1-\theta) p F_{L} / p_{L}+(1-c) \pi$ and the corresponding net real return is $(1-\theta) p F_{L} / p_{L}-c \pi$. For real capital, the real net return is $(1-\theta)\left(F_{k}-\lambda \pi\right)-c \pi$. The equality of these two real net returns thus implies:

$$
\frac{p_{L}}{p}=\frac{F_{L}}{F_{k}-\lambda \pi}
$$

Because depreciation for tax purposes understates true depreciation, the real net yield on capital is reduced and the price of land rises relative to the price of reproducible capital. Only after this adjustment in relative prices has occurred will both assets increase in price at the same rate $\pi$, as indicated in (3).

It is useful to introduce bonds and to restate this analysis for an investor who equates the real net yield on land with the real net yield on bonds. ${ }^{10}$ The key distinction between bonds and either capital or land is the absence of a nominal capital gain. Instead, the interest rate paid on these bonds rises with inflation. It is important, however, that this interest premium is subject to the ordinary rate of income tax while the nominal capital gain on land is taxed at the lower capital gains tax rate. Thus, if $r$ is the nominal rate of interest, the net nominal yield on bonds is $(1-\theta) r$ and the net real yield is $(1-\theta) r-\pi$.

Equality of the net real yields on land and bonds

$$
\frac{(1-\theta) p F_{L}}{P_{L}}-c \pi=(1-\theta) r-\pi
$$

implies

$$
\frac{p_{L}}{p}=\frac{(1-\theta) F_{L}}{(1-\theta) r-(1-c) \pi}
$$

Since $F_{L}$ remains constant, the value of $p_{L} / p$ depends on how the nominal interest rate responds to inflation. Equation (6) implies that $p_{L} / p$ increases with inflation if

$$
\frac{d r}{d \pi}<\frac{1-c}{1-\theta}
$$

In the United States it has long been true that the nominal interest rate rises by approximately the rate of inflation, i.e., that $d r / d \pi=1$ provides a

10. Although the maturity of the bond is irrelevant for discussing the steady-state equilibrium, the transition is easier to consider if these bonds are assumed to have very short maturities as Treasury bills do. 
close approximation of historical experience." Thus, since the effective capital gains tax rate is less than the ordinary income rate $(c<\theta)$, the inequality in (7) has been satisfied and inflation causes $p_{L}$ to rise relative to $p$.

Although this simple model is able to capture the essential reason why the relative price of land varies positively with the expected inflation rate, it is easy to show that this model is not sufficient to determine the effect of inflation on the price of gold and other "pure" stores of real value. For the current purpose, the basic difference between land and gold is that gold has no real marginal product. The equilibrium net return on gold is simply the nominal gain caused by general inflation, $(1-c) \pi$. The corresponding real return is thus $-c \pi$; gold has a negative real return to the extent that a capital gains tax must be paid on the nominal gain. Since the net real return on bonds is $(1-\theta) r-\pi$, the equality of real net returns requires

$$
(1-c) \pi=(1-\theta) r
$$

Even if condition (8) holds, it does not imply anything about the price of gold. Moreover, this condition would hold for different values of $\pi$ only if $d r / d \pi=(1-c) /(1-\theta)$. Since this condition has not in fact been true, this model of investor equilibrium implies complete specialization by investors in gold or bonds. ${ }^{12}$ What is clearly needed is a more general model of portfolio behavior. The next section presents such a model and examines its implications for the prices of gold and land.

\subsection{A Portfolio Equilibrium Model of the Prices of Gold and Land}

The simplest of all models of portfolio equilibrium is the condition that real net asset yields must be equal. Although this model, which implicitly assumes that the assets are perfect substitutes, may be useful for some purposes, it is clearly inadequate for analyzing the effect of inflation on the price of gold. The risks associated with holding bonds and gold are clearly different. The current section therefore presents a slightly more general model of portfolio equilibrium. After discussing the implied effect of inflation on the equilibrium relative price of gold, the model is used to extend the previous analysis of the price of land.

In place of the assumption of perfect substitutability, the current section states that the demand for gold relative to the demand for bonds is

11. This empirical result has been supported by evidence since Irving Fisher's (1930) classic study. For more recent evidence, see Yohe and Karnovsky (1969), Feldstein and Eckstein (1970), and Feldstein and Summers (1977). This behavior of the interest rate reflects both tax rules and monetary pollcy; see Feldstein (1980c; chap. 5 above).

12. In a more general model with more than one class of investor, differences in tax situations will cause complete specialization of asset holdings if investors disregard risk and will not hold any asset when a higher yielding alternative is available. 
a linear function of the difference between the expected real net yields. If the fixed physical amount of gold is $G$, and its price is $p_{G}$, the nominal value of gold in investors' portfolios is $p_{G} G{ }^{13}$ To simplify the analysis further, I will assume a fixed real quantity of debt, $B$; the nominal value of the debt is thus $p B$. Since the real net yield on gold is $-c \pi$ and the real net yield on bonds is $(1-\theta) r-\pi$, the portfolio equation will be written

$$
\frac{p_{G} G}{p B}=\gamma_{0}+\gamma_{1}[(1-c) \pi-(1-\theta) r]
$$

Since the demand for gold is an increasing function of the expected yield differential, $\gamma_{1}>0$; as $\gamma_{1}$ tends to infinity, this model tends to the earlier model of equal yields as a condition for equilibrium. With $\gamma_{0}>0$, there is a positive demand for gold even when the expected real net yield on gold is less than the corresponding yield on bonds.

Since $G$ and $B$ are constant, (9) implies that the relative price of gold is an increasing function of inflation if

$$
\frac{d r}{d \pi}<\frac{1-c}{1-\theta}
$$

This is the same condition as inequality (7). As I noted there, this condition has been true empirically in the United States for a long time. The simple model of portfolio equilibrium thus implies that an increase in the expected equilibrium rate of inflation raises the relative price of gold. In the new equilibrium, of course, the relative price of gold remains unchanged.

More generally, the effect of an increase in the expected rate of inflation is to reduce the real yield on gold by $c \cdot d \pi$ while it reduces the real yield on bonds by $d \pi-(1-\theta) d r$. With the empirical approximation that $d r / d \pi=1$, this implies that the yield on gold is reduced less than the yield on bonds if $c<\theta$, i.e., if the capital gains tax rate is less than the ordinary income tax rate. Since this is satisfied for all taxable investors, inflation shifts the yield differential in favor of gold. For quite a wide range of plausible assumptions, this change in demand can be expected to increase the relative price of gold. Note finally that in a simpler economy with no taxes on capital income $(\theta=c=0)$, inflation has no effect on the relative price of gold if $d r / d \pi=1$.

Applying the same portfolio model to land is only slightly more complex. Since the real net yield on land is $(1-\theta) p F_{L} / p_{L}-c \pi$, the portfolio equilibrium equation analogous to $(9)$ becomes $^{14}$

13. Treating the amount of gold as fixed implicitly assumes a closed economy. More generally, the world price of gold will depend on the demands of investors in different countries and, therefore, on their inflation rates and tax policies.

14. It would clearly be desirable to have a more general model in which the demand for each kind of asset depends on the relative yields of all assets. The current pairwise 


$$
\frac{p_{L} L}{p B}=\delta_{0}+\delta_{1}\left[\frac{(1-\theta) p F_{L}}{p_{L}}+(1-c) \pi-(1-\theta) r\right]
$$

Totally differentiating this equation yields

$$
\frac{d\left(p_{L} / p\right)}{d \pi}=\frac{\delta_{1}\left[(1-c)-(1-\theta) \frac{d r}{d \pi}\right]}{\frac{L}{B}+\delta_{1}(1-\theta) F_{L} p^{2} p_{L}^{-2}}
$$

Since the denominator is unambiguously positive, the sign of the derivative depends on the sign of the numerator. It is easy to see that this is positive if the inequality of $(10)$ is satisfied. Thus, if $d r / d \pi<(1-c) /$ $(1-\theta)$, the simple portfolio behavior considered here implies that the relative price of land is positively related to the expected rate of inflation.

It is not possible to evaluate the magnitude of the relative price change without knowing the value of $\delta_{1}$. An indication of the possible magnitude can be obtained, however, for the special case in which the real net yields on land and bonds are either equal or differ only by a constant. The portfolio equilibrium condition

$$
\frac{(1-\theta) p F_{L}}{p_{L}}-c \pi=(1-\theta) r-\pi+\beta
$$

where $\beta$ is an arbitrary constant yield differential, implies

$$
\frac{d\left(p F_{L} / p_{L}\right)}{d \pi}=\frac{d r}{d \pi}-\frac{1-c}{1-\theta}
$$

With the approximation that $d r / d \pi=1$, this implies that

$$
\frac{d\left(p F_{L} / p_{L}\right)}{d \pi}=-\left(\frac{\theta-c}{1-\theta}\right)
$$

Reasonable values of the tax parameters for individual investors may be taken as $\theta=0.4$ and $c=0.15$. These imply that the pretax real yield on land falls by 0.4 times the change in inflation. An inflation rate of $\pi=$ 0.06 thus reduces the real pretax yield by 0.024 . If the initial real pretax yield is 0.08 , a 6 percent inflation reduces the yield by 30 percent. Since the physical marginal product of land $\left(F_{L}\right)$ is constant, a 30 percent reduction in $p F_{L} / p_{L}$ implies that $p / p_{L}$ falls by 30 percent; thus the relative price of land rises by 43 percent. Similarly, a 10 percent rate of inflation would reduce $p F_{L} / p_{L}$ from 0.08 to 0.04 , implying a doubling of the relative price of land. While these calculations are very crude and are likely to

comparison with the yield on debt is obviously a strong simplification. It is sufficient, however, to provide an interesting generalization of the even simpler model of the previous section. 
overstate the response of the land price that would be implied by a more general portfolio model, they do suggest that even a relatively small increase in the rate of inflation can have a very substantial effect on the price of land. Since gold lacks any real marginal product, its relative price is likely to be more sensitive to the expected rate of inflation.

\subsection{Concluding Comments}

This paper has presented a simple analysis of the relation between the expected rate of inflation and the prices of land, gold, and other nondepreciating real stores of value. In contrast to the traditional theoretical conclusion that relative prices are unaffected by the rate of inflation, the current analysis shows that, because of unindexed taxes on capital income, a higher expected rate of inflation raises the prices of land and gold relative to the general price level of produced goods. More generally, as I have noted in earlier papers, a change in the expected equilibrium rate of inflation alters the real net rate of interest, the stock market value of real capital, and the real net marginal product of investment. In an economy with capital income taxes, inflation is far from neutral.

The very rapid rise in the relative prices of land, gold, and other such assets during the recent decade of rising inflation rates is, of course, consistent with the view presented in this paper. The actual course of these prices may also have reflected such things as an increased attention to inflation, a belief that future inflation rates have become more uncertain, increased speculative demand, and changes in statutory tax rules. But even without these transitional or disequilibrium elements, the current analysis shows that changes in expected inflation can have powerful effects on the relative prices of such investment assets.

It would clearly be desirable to extend the current model by developing an explicit theory of portfolio equilibrium for investors who hold land, gold, bonds, and equity shares. The real yields on these assets would be linked because they are all dependent upon future changes in expected inflation. As a further step, the analysis should recognize that the effect of inflation on each individual's demand for each asset depends on that individual's own tax situation. The equilibrium market price can then be derived as the market clearing solution to the individuals' separate asset demand equations. ${ }^{15}$

15. Feldstein ( $1980 b, d$; chaps. 9 and 10 above) derives such a solution to the problem of valuing equity shares when there are two classes of investors in very different tax situations. 